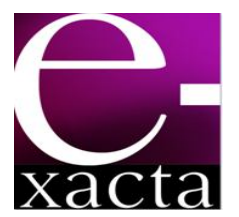

ISSN: 1984-3151

\section{CARVÃO ATIVADO GRANULAR IMPREGNADO COM ZINCO PARA REMOÇÃO DE BACTÉRIAS DA ÁGUA PARA CONSUMO HUMANO}

\author{
GRANULAR ACTIVATED CARBON IMPREGNATED WITH ZINC FOR \\ REMOVAL OF BACTERIA FROM DRINKING WATER
}

\author{
Flávia Sayuri Arakawa'; Quelen Letícia Shimabuku²; Priscila Ferri Coldebella ${ }^{3}$; Franciele \\ Pereira Camacho ${ }^{4}$; Fernando Alves da Silva ${ }^{5}$; Gleicielle Tozzi Wurzler6; Taíse Bonfim \\ Martins $^{7}$; Simone de Lima Bazana ${ }^{8}$; Onélia Aparecida Andreo dos Santos ${ }^{9}$; Rosângela \\ Bergamasco $^{10}$
}

1 Mestre em Engenharia Química. Universidade Estadual de Maringá, 2011. Doutoranda em Engenharia Química PEQ/UEM. Maringá, PR. flaviasayuri@gmail.com.

2 Mestre em Engenharia Química. Universidade Estadual de Maringá, 2011. Doutoranda em Engenharia Química PEQ/UEM. Maringá, PR. le.shimabuku@gmail.com.

3 Mestre em Engenharia Agrícola. Universidade Estadual do Oeste do Paraná, 2006. Doutoranda em Engenharia Química PEQ/UEM. Maringá, PR. priscila.ferri@bol.com.br.

4 Mestre em Engenharia Química. Universidade Estadual de Maringá, 2012. Doutoranda em Engenharia Química PEQ/UEM. Maringá, PR. franciele camacho@hotmail.com.

5 Graduação em Engenharia Química. Universidade Estadual de Maringá, 2013. Mestrando em Engenharia Química PEQ/UEM. Maringá, PR. dk nanduu@hotmail.com.

6 Graduação em Engenharia Química. Universidade Estadual de Maringá, 2013. Mestranda em Química IME. Rio de Janeiro, RJ.gleicytw@hotmail.com.

7 Graduação em Engenharia Química. Universidade Estadual de Maringá, 2013. taise1590@gmail.com.

8 Graduação em Tecnologia em Meio Ambiente. Universidade Estadual de Maringá, 2006. Mestranda em Engenharia Química PEQ/UEM. Maringá, PR. slbazana@yahoo.com.br.

9 Doutora em Engenharia Química. Universidade Estadual de Campinas, 1999. Professora da Universidade Estadual de Maringá - UEM. Maringá, PR. onelia@deq.uem.br.

10 Doutora em Engenharia Química. Universidade Estadual de Campinas, 1996. Professora da Universidade Estadual de Maringá - UEM. Maringá, PR. rosangela@deq.uem.br.

Recebido em: 10/09/2013 - Aprovado em: 12/11/2013 - Disponibilizado em: 30/11/2013

RESUMO: O carvão ativado granular impregnado com zinco (C/Zn) foi avaliado em relação à atividade antibacteriana para eliminação de micro-organismos na purificação de água para consumo humano. Os meios filtrantes produzidos a partir de C/Zn foram caracterizados através de técnicas instrumentais como análises de $B E T$ e difração de raios- $X(D R X)$ para determinar a distribuição de poros e área superficial e as fases estruturais, respectivamente. Experimentos foram realizados em um sistema doméstico de purificação de água utilizando filtros com leito de carvão ativado granular sem impregnação e com impregnação de zinco nas concentrações de 
1,0, 3,0, 5,0 e 10,0\% (m/m). A atividade antibacteriana dos meios filtrantes foi avaliada em relação à eficiência de remoção de bactérias Escherichia coli da água. Foram preparadas soluções sintéticas com água deionizada

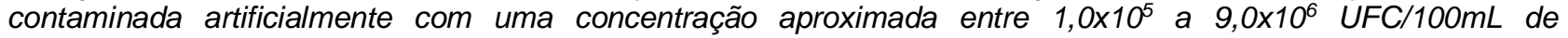
Escherichia coli. Assim a eficiência bacteriológica dos meios filtrantes com C/Zn foi superior com o aumento da concentração de zinco impregnado no carvão ativado. O filtro com leito de carvão ativado impregnado com $10 \%$ de zinco apresentou a maior eficiência com remoção de Escherichia coli superior a 99\% e melhorando a qualidade bacteriológica da água para consumo humano.

PALAVRAS-CHAVE: Carvão ativado granular. Impregnação. Zinco. Purificação de água.

ABSTRACT: Granular activated carbon impregnated with zinc $(C / Z n)$ was evaluated for the antibacterial activity for elimination of micro-organisms in drinking water purification. The filter media produced from C/Zn were characterized by instrumental techniques such as the BET analyzes and x-ray diffraction (XRD) to determine the pore distribution and surface area and structural phases, respectively. Experiments were performed in a household water purification system using filters with granular activated carbon bed without impregnation and impregnation with zinc in concentrations of 1.0, 3.0, 5.0 and $10.0 \%(\mathrm{w} / \mathrm{w})$. The antibacterial activity of the filter media was evaluated regarding to the removal efficiency of bacteria Escherichia coli of water. Synthetic solutions were prepared with deionized water contaminated artificially with an approximate concentration of $1.0 \times 10^{5}$ to $9.0 \times 10^{6}$ CFU/100mL of Escherichia coli. The efficiency bacteriological efficiency bacteriological of filter media with $\mathrm{C} / \mathrm{Zn}$ was higher with increasing concentration of zinc impregnated on activated carbon. The filter bed of activated carbon impregnated with $10 \%$ of zinc showed the highest efficiency with removal of bacterial Escherichia coli higher than $98 \%$ and improving the bacteriological quality of drinking water.

KEYWORDS: Granular activated carbon. Impregnation. Zinc. Drinking water purification.

\section{INTRODUÇÃO}

A poluição da água é um dos principais problemas enfrentados pela humanidade, e a maioria das doenças transmitidas pela água é disseminada por causa da sua má qualidade devido à presença de bactérias e vírus (KENNEDY et al., 2007). Um dos aspectos mais importantes para a melhoria da saúde da população é a garantia de uma água para consumo com qualidade assegurada, que seja potável e livre de organismos patogênicos como vírus, bactérias e protozoários.

O principal indicador da qualidade sanitária da água potável são os coliformes, mais especificamente a Escherichia coli, que fazem parte da microbiota intestinal do homem e outros animais de sangue quente. Esses microrganismos, quando detectados em uma amostra de água, fornecem evidência direta de contaminação fecal recente, e por sua vez podem indicar a presença de outros microrganismos patogênicos, especialmente protozoários e vírus entéricos. (POPE et al., 2003; HÖRMAN et al., 2004;
MCQUAIG et al., 2006; PETER-VARBANETS et al., 2009). Escherichia coli é responsável por patologias como pneumonias, meningites, infecções intestinais, diarreias moderadas a severas e pela síndrome hemolítica urêmica (SHU) em todos os grupos etários, levando o indivíduo à morte, quando o tratamento não é efetuado corretamente e em tempo hábil (ZIESE et al.,1996).

Existem outras fontes de contaminação microbiana de águas superficiais e subterrâneas, tais como: lixiviação de substâncias naturais do solo, descargas de tratamento de esgoto e instalações industriais (GOPAL et al., 2007). Em alguns casos, a contaminação fecal também pode ser proveniente do uso de dejetos animais na fertilização do solo (GARCIA-ARMISEN; SERVAIS, 2007; BERTRAND; ROIG, 2007). Com a falta de saneamento, sobretudo nas áreas menos desenvolvidas ou mais pobres, esta contaminação fecal torna-se um problema de saúde pública, considerando-se que grande parte desta população não tem acesso à água tratada. 
Portanto, intervenções para controlar e manter a qualidade microbiológica da água levam à necessidade da aplicação de tecnologias apropriadas de tratamento (SU et. al., 2009). O carvão ativado vem sendo utilizado como uma eficiente alternativa para a purificação de águas (HAMDAOUI; NAFFRECHOW, 2007; CHENG; DASTGHEIB; KARANFIL, 2005). Devido a sua estrutura porosa altamente desenvolvida, o carvão ativado possui uma grande capacidade adsorvente para remover o sabor e o odor da água, eliminar contaminantes orgânicos e inorgânicos, gases tóxicos, pesticidas, reduzir a matéria orgânica natural, limitando assim ao máximo a formação de subprodutos de desinfecção e/ou oxidação, como os trihalometanos, substâncias comprovadamente cancerígenas (PHAN et al., 2006; AKSU; TATH; TUNÇ, 2008).

No entanto, o carvão ativado sozinho não é eficiente contra bactérias, vírus ou protozoários (NANGMENYI et al., 2009). Carvão ativado impregnado com metais tem sido aplicado devido aos seus efeitos antibacterianos $(\mathrm{OH}, 2003)$.

Diversos estudos sobre a impregnação de metais com atividade antimicrobiana, particularmente a prata, na superfície do carvão ativado têm sido reportados por Zhao et al. (2013), Bandyopadhyaya; Sivaiah; Shankar (2008) e Maioli et al. (2009). No entanto, neste trabalho foi avaliado o efeito bactericida de outro metal, o zinco. Este em quantidades adequadas é um elemento essencial e benéfico para o metabolismo humano, sendo que a atividade da insulina e diversos compostos enzimáticos dependem da sua presença. $A$ deficiência do zinco no organismo pode conduzir ao atraso no desenvolvimento, crescimento e anemia. (PAREY, 1999). O zinco possui atividades celulares básicas, como replicação do DNA, transcrição, divisão e ativação celular. Contudo, é conhecido por ser estabilizador de membranas e de várias macromoléculas (CHOUDHURYR; SRIVASTAVA, 2001). O zinco interage no metabolismo das células bacterianas, necessitando de maiores concentrações para que seja tóxico, também interage com ácidos nucleicos e sítios ativos de enzimas, diminuindo assim a saúde da membrana celular e eventualmente levando a célula à necrose (CHOUDHURYR; SRIVASTAVA, 2001; SILVER; WALDERHAUG, 1992).

O presente trabalho teve como objetivo preparar e caracterizar meios filtrantes produzidos a partir de carvão ativado granular vegetal modificado pela impregnação de zinco e avaliar a eficiência de remoção de bactérias Escherichia coli da água para consumo humano.

\section{MetodologiA}

\subsection{Preparação do carvão ativado GRANULAR IMPREGNADO COM ZINCO}

Carvão ativado granular de coco de dendê (Bahiacarbon, Bahia, Brasil), com granulometria entre 20X50 mesh, foi preparado pelo método de impregnação com excesso de solvente em soluções preparadas com diferentes concentrações de zinco $(\mathrm{m} / \mathrm{m})$ a $1,0 \%$ (C/Zn1,0\%), 3,0\% (C/Zn3,0\%), 5,0\% (C/Zn5,0\%), e 10,0\% (C/Zn10,0\%). Em um evaporador rotativo (Modelo 804, Marca Fisatom), foram adicionados as soluções aquosas com quantidade suficiente de $\mathrm{ZnCl}_{2}$ (Vetec Ltda), $150 \mathrm{~mL}$ de água deionizada e $150 \mathrm{~g}$ de carvão ativado granular. A impregnação de zinco na estrutura do carvão ativado granular foi obtida por meio de agitação (20 rpm) à temperatura de $60 \stackrel{\circ}{\circ} / 24 \mathrm{~h}$. As amostras foram secas em estufa de ar (Modelo SXCR/42, Marca Sterilifer) à temperatura de $100{ }^{\circ} \mathrm{C} / 24 \mathrm{~h}$. As amostras foram submetidas a um tratamento térmico em forno mufla (Modelo Q318J3ST, Marca Quimis) à temperatura de $350^{\circ} \mathrm{C} / 5 \mathrm{~h}$. 


\subsection{Caracterização do carvão ativado GRANULAR IMPREGNADO COM ZINCO}

\subsection{1 ÁREA SUPERFICIAL E DISTRIBUIÇÃO DO TAMANHO DE POROS}

A área superficial e a distribuição do tamanho de poros foram realizadas em um sistema de sorção de gás Autosorb (Modelo, Nova 1200 Series, Marca Quantachome Corporation) obtidas das isotermas de adsorção/dessorção de nitrogênio $\left(\mathrm{N}_{2}\right)$ a $77 \mathrm{~K}$. As isotermas relacionam a quantidade de gás adsorvido a uma dada temperatura para diferentes pressões relativas. A análise das isotermas de adsorção fornecidas por este método permite caracterizar a estrutura porosa dos adsorventes, como recomendado pela União Internacional de Química Pura e Aplicada (IUPAC) (GAUDEN et al., 2006). Foram obtidas propriedades como área superficial BET ( $\left.\mathrm{S}_{\mathrm{BET}}\right)$, calculada usando a equação de Brunauer-EmmettTeller (BRUNAUER; EMMETT; TELLER,1968), área de microporos $\left(\mathrm{S}_{\mathrm{m}}\right)$ determinada através do método $\mathrm{t}$ de Halsey (HALSEY, 1948), volume de poros $\left(V_{p}\right)$, e o diâmetro médio dos poros $\left(d_{p}\right)$ foi calculado utilizandose a equação de Horvath-Kawazoe (HK), derivada de forma independente a partir da equação Kelvin (HORVATH; KAWAZOE, 1983).

\subsubsection{DIFRAÇÃO DE RAIO-X (DRX)}

A caracterização estrutural foi realizada em Difratômetro de Raio-X (Modelo D6000, Marca Shimadzu) através de análises de Difração de Raio-X (DRX). A técnica identifica as fases cristalinas ou amorfas das microestruturas do carvão ativado granular após a impregnação. Os difratogramas de Raios-X das amostras foram obtidos com ângulos de difração variando na faixa dos valores de $2 \theta$ entre $20^{\circ}$ a $70^{\circ}$ usando radiação $\mathrm{Cu}-\mathrm{K}_{\alpha}(\lambda=0.15418 \mathrm{~nm})$.

\subsection{EXPERIMENTOS DE ATIVIDADE ANTIBACTERIANA}

Os testes de eficiência bacteriológica foram realizados em um sistema gravitacional de purificação de água para consumo humano. As amostras com carvão ativado impregnado com zinco $(\mathrm{C} / \mathrm{Zn})$ e a amostra de carvão ativado sem impregnação (C Puro) foram empacotadas em leitos cilíndricos de 90x72 mm contendo $150 \mathrm{~g}$ de carvão em cada leito e foram fixadas no lugar dos filtros comerciais domésticos. Para verificação da eficiência antibacteriana de cada leito, foram percolados $10 \mathrm{~L}$ de solução sintética preparada com água estéril contaminada com Escherichia coli (ATCC 11229) na concentração variando entre $1,0 \times 10^{5}$ e $9,0 \times 10^{6}$ UFC/100mL, conforme descrito na Norma Brasileira ABNT NBR 16098/2012 - Aparelho para melhoria da qualidade da água de uso doméstico - Aparelho por gravidade (ABNT, 2012). A solução sintética preparada foi filtrada nos leitos de carvão e as amostras de água foram coletadas antes e depois da filtração. As amostras de água foram analisadas utilizando-se a técnica da membrana filtrante para o grupo de coliformes, como descrito no Standard Methods for Examination of Water and Wastewater (APHA, 2005). Os testes foram realizados na condição inicial $(5 \%)$ e na condição final (95\%) da vida útil dos filtros, estipulando a vida útil com filtração de um volume de $600 \mathrm{~L}$ de água de abastecimento.

O critério de eficiência bacteriológica mínima para o contaminante Escherichia coli estabelecido pela ABNT NBR 16098/2012 é redução de 99\% (2 log), e de acordo com a Portaria do Ministério da Saúde 2914/2011 (BRASIL, 2011), o critério para avaliação é classificado com ausência em $100 \mathrm{~mL}$ da amostra. 
Para analisar a atividade antibacteriana, realizou-se a Análise de Variância (ANOVA) e 0 teste de comparação de médias, teste Tukey, com $95 \%$ de confiança, sendo significativo um $p$-valor $<0,05$, para verificar o filtro com a maior eficiência bacteriológica e avaliar a diferença na eficiência entre a condição inicial $(5 \%)$ e condição final (95\%) da vida útil dos filtros, utilizando o programa estatístico Statistica, versão 8.0.

\subsection{DeterminaçÃo de EXTRAíveis}

As análises para determinação de extraíveis permitiu verificar se o zinco impregnado no carvão ativado granular eventualmente tenha sido liberado na água filtrada após a percolação em cada leito e se encontram dentro dos limites permitidos pela ABNT NBR 16098/2012 e pela Portaria 2914/2011, que estabelecem um limite máximo de concentração de extraíveis para o parâmetro zinco de $5,0 \mathrm{mg} \cdot \mathrm{L}^{-1}$. Os testes foram realizados na condição inicial (5\%) e final (95\%) da vida útil dos filtros, conforme estabelecido pela ABNT NBR 16098/2012. As análises das concentrações do metal foram realizadas como descrito no Standard Methods for the Examination of Water and Wastewater (APHA,2005) e determinadas por espectrometria de absorção atômica (Modelo SpetrAA 50 B, Marca Varian).

Para verificar a concentração de zinco lixiviada na água filtrada de cada filtro com $\mathrm{C} / \mathrm{Zn}$, realizou-se a Análise de Variância (ANOVA) e 0 teste de comparação de médias, teste Tukey, com $95 \%$ de confiança, sendo significativo um $p$-valor $<0,05$, utilizando o programa estatístico Statistica, versão 8.0.

\section{Resultados e Discussão}

\subsection{Caracterização do carvão ativado GRANULAR IMPREGNADO COM ZN}

\subsection{1 ÁREA SUPERFICIAL E DISTRIBUIÇÃo dO TAMANHO DE POROS}

A isoterma de adsorção e dessorção de nitrogênio a $77 \mathrm{~K}$, obtida pela classificação segundo Brunauer, Emmet e Teller (classificação BET) para a amostra de carvão ativado granular sem impregnação (C Puro), é mostrada na FIG. 1.

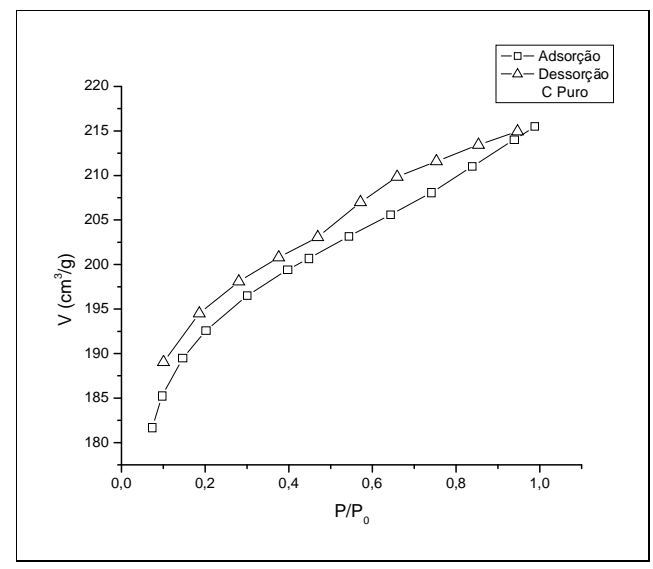

Figura 1 - Isoterma de adsorção e dessorção da amostra de carvão ativado sem impregnação (C puro)

A isoterma de adsorção e dessorção obtida foi aproximadamente do Tipo I e Tipo IV. A isoterma do Tipo I, também conhecida como isoterma de Langmuir, é côncava para o eixo $P / P_{0}$, e se aproxima de um valor limite conforme $\mathrm{P} / \mathrm{P}_{0}$ se aproxima de 1 . A isoterma de Tipo I está relacionada com a adsorção em microporos, e a região da curva apresenta-se praticamente vertical, devido à grande facilidade de adsorção em poros com diâmetros menores que $2 \mathrm{~nm}$, que corresponde à monocamada completa (QUANTACHROME, 2002). Isotermas do Tipo IV fornecem informações sobre a estrutura dos mesoporos através da histerese, que é a não sobreposição da seção da adsorção e da dessorção. 
A histerese apresentada é de Tipo A, característica de mesoporos da forma cilíndrica.

Nas FIG. 2, FIG. 3, FIG. 4 e FIG. 5, são apresentadas as isotermas de adsorção e dessorção de nitrogênio a $77 \mathrm{~K}$, obtidas para as amostras $\mathrm{C} / \mathrm{Zn} 1,0 \%, \mathrm{C} / \mathrm{Zn} 3,0 \%$, C/Zn5,0\% e C/Zn10,0\% respectivamente.

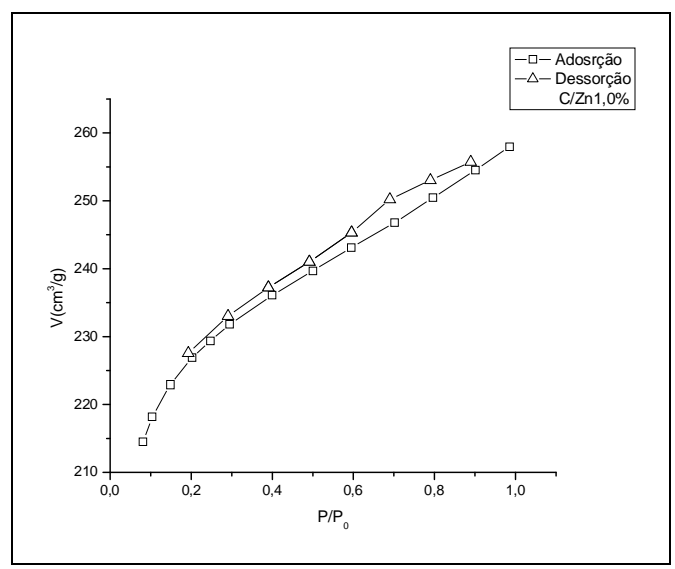

Figura 2 - Isoterma de adsorção e dessorção da amostra de carvão impregnado com $1,0 \%$ de zinco (C/Zn1,0\%)

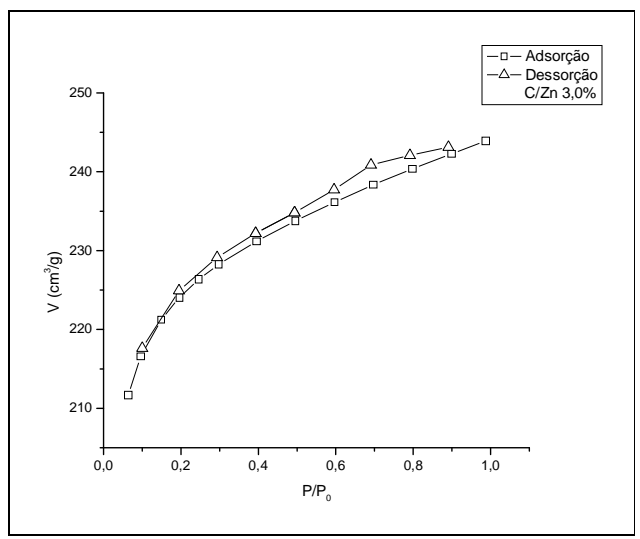

Figura 3 - Isoterma de adsorção e dessorção da amostra de carvão impregnado com 3,0\% de zinco $(\mathrm{C} / \mathrm{Zn} 3,0 \%)$

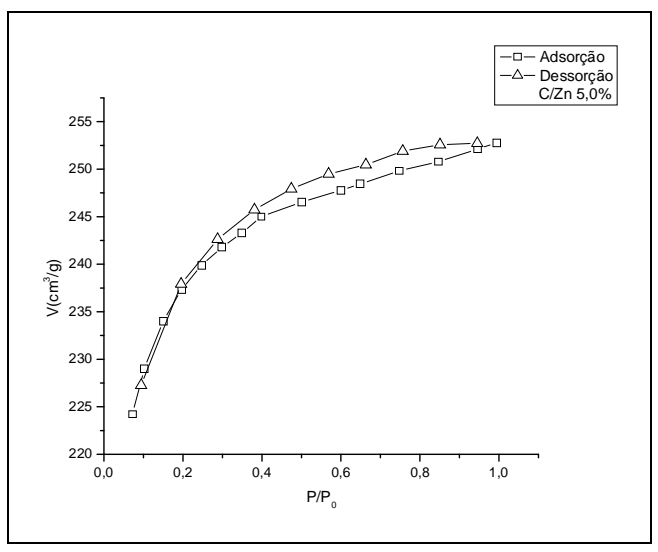

Figura 4 - Isoterma de adsorção e dessorção da amostra de carvão impregnado com 5,0\% de zinco $(\mathrm{C} / \mathrm{Zn} 5,0 \%)$

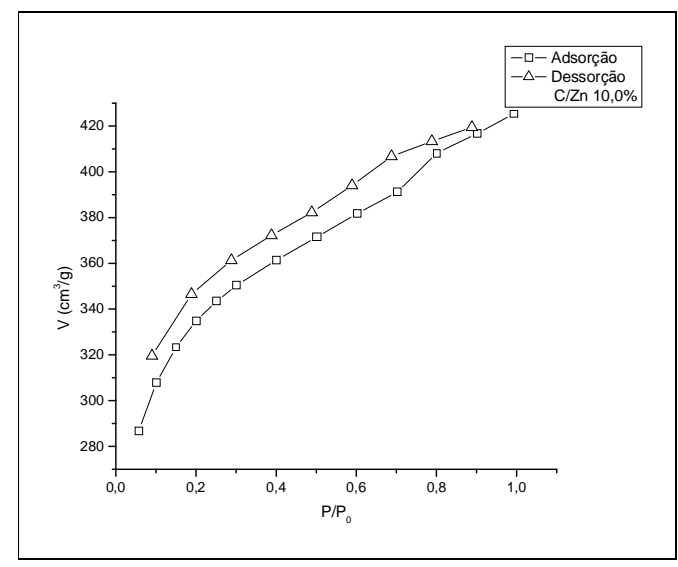

Figura 5 - Isoterma de adsorção e dessorção da amostra de carvão impregnado com 10,0\% de zinco $(\mathrm{C} / \mathrm{Zn} 10,0 \%)$

As isotermas obtidas para todas as amostras de $\mathrm{C} / \mathrm{Zn}$ foram similares à obtida para a amostra de carvão ativado sem impregnação (C Puro), ou seja, são isotermas do Tipo I e Tipo IV, associadas à microporos e mesoporos, e a histerese apresentada por elas está relacionada a poros cilíndricos, indicando que a impregnação de zinco e o tratamento térmico aplicado às amostras de carvão ativado praticamente não modificaram as características da estrutura porosa do carvão.

Os efeitos da impregnação de zinco nas propriedades texturais do carvão ativado granular são mostrados na TAB. 1, onde área superficial específica 
$\operatorname{BET}\left(\mathrm{S}_{\mathrm{BET}}\right)$, área de microporos $\left(\mathrm{S}_{\mathrm{m}}\right)$, volume de poros $\left(V_{p}\right)$ e diâmetro médio dos poros $\left(d_{p}\right)$ foram analisados na amostra de carvão ativado granular sem impregnação e nas amostras impregnadas com C/Zn.

Da TAB. 1, é possível observar que todas as amostras analisadas apresentaram áreas superficiais relativamente altas quando comparadas com outros autores (JAGUARIBE, 2005; RAZVIGOROVA et al., 1998; SORLINI; COLLIVIGNARELLI, 2005; YAMAMOTO et al., 2001; GAUDEN et al., 2006).

Tabela 1

Propriedades texturais do carvão ativado granular sem impregnação (C puro) e das amostras de carvão ativado granular impregnado com zinco $(\mathrm{C} / \mathrm{Zn}) \mathrm{em}$ diferentes concentrações

\begin{tabular}{ccccc}
\hline Amostra & $\begin{array}{c}\mathrm{S}_{\text {BET }} \\
\left(\mathrm{m}^{2} \mathrm{~g}^{-1}\right)\end{array}$ & $\begin{array}{c}\mathrm{S}_{\mathrm{m}} \\
\left(\mathrm{m}^{2} \mathrm{~g}^{-1}\right)\end{array}$ & $\begin{array}{c}\mathrm{V}_{\mathrm{p}} \\
\left(\mathrm{cm}^{3} \mathrm{~g}^{-1}\right)\end{array}$ & $\mathrm{d}_{\mathrm{p}}(\mathrm{nm})$ \\
\hline C puro & 870 & 743 & 0,4127 & 16 \\
C/Zn 1,0\% & 723 & 671 & 0,3433 & 15 \\
$\mathrm{C} /$ Zn 3,0\% & 691 & 596 & 0,3405 & 14 \\
C/Zn 5,0\% & 667 & 579 & 0,3401 & 15 \\
C/Zn10,0\% & 594 & 533 & 0,2897 & 15 \\
\hline
\end{tabular}

A área superficial mais alta foi apresentada pelo carvão ativado puro, de $870 \mathrm{~m}^{2} \cdot \mathrm{g}^{-1}$. Observou-se que ocorreu uma ligeira diminuição da área superficial do carvão ativado depois do processo de impregnação. Além da área superficial específica $\left(\mathrm{S}_{\mathrm{BET}}\right)$, a área de microporos $\left(\mathrm{S}_{\mathrm{m}}\right)$, o volume de poros $\left(\mathrm{V}_{\mathrm{p}}\right)$ e o diâmetro médio de poros $\left(d_{p}\right)$ das amostras impregnadas com $\mathrm{C} / \mathrm{Zn}$ diminuíram gradativamente, à medida que aumentou a concentração de zinco impregnada no carvão ativado granular.

A porcentagem de microporos e mesoporos para cada uma das amostras analisadas está apresentada na TAB. 2. Estes resultados reforçam a possibilidade de 0 zinco ter sido impregnado no interior dos poros, diminuindo seu diâmetro, sobretudo para a amostra $\mathrm{C} / \mathrm{Zn} 1,0 \%$.

Tabela 2

Porcentagem de microporos e mesoporos

\begin{tabular}{ccc}
\hline Amostra & Microporos (\%) & Mesoporos (\%) \\
\hline C puro & 85,40 & 14,60 \\
C/Zn 1,0\% & 92,80 & 7,20 \\
C/Zn 3,0\% & 86,25 & 13,75 \\
C/Zn 5,0\% & 86,80 & 13,20 \\
C/Zn 10,0\% & 89,73 & 10,26 \\
\hline
\end{tabular}

\subsubsection{Difração de RaIO-X (DRX)}

Os difratogramas de Raio- $X$ para as amostras impregnadas com zinco (C/Zn1,0\%, C/Zn3,0\%, C/Zn5,0\%, C/Zn10,0\%), em comparação com o difratograma do carvão ativado sem impregnação (C Puro), são mostrados na FIG. 6.

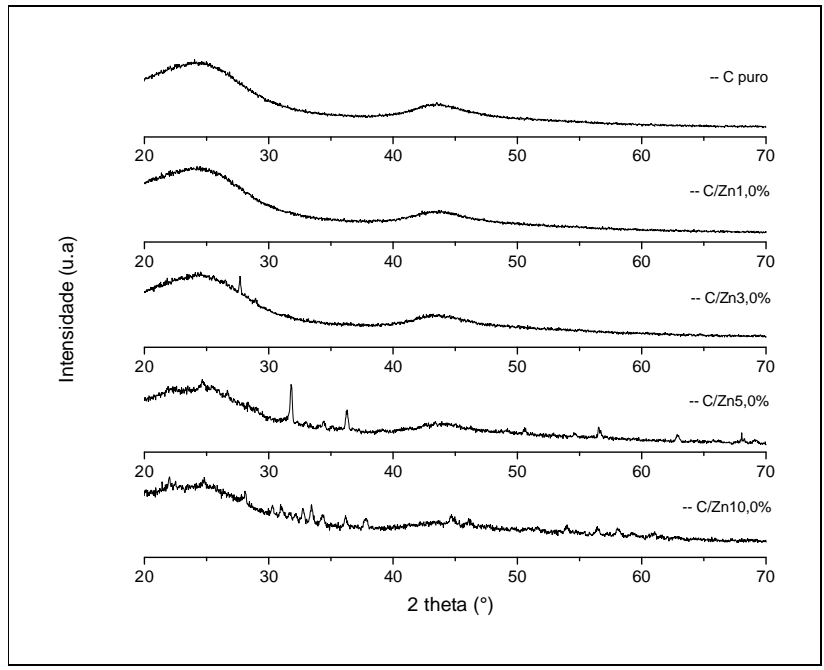

Figura 6 - Difratogramas de raio-X para as amostras impregnadas com zinco (C/Zn) em comparação com o carvão ativado puro (C puro).

Os difratogramas revelaram que para o carvão ativado puro, assim como para todas as amostras impregnadas com zinco, foram localizados picos correspondentes ao plano de carbono e carbono 
grafite. Os picos em valores de $2 \theta$ próximos de $23,98^{\circ}$ e $27,43^{\circ}$ referem-se ao plano basal de carbono. O pico próximo a $2 \theta$ próximo de 44,39 indica que os poros também foram formados pela decomposição de estruturas de carbono ao longo da direção de umas das estruturas de grafite (YUN; PARK; PARK, 2001). $\mathrm{Na}$ amostra $\mathrm{C} / \mathrm{Zn} 1,0 \%$ não foi observada interferência do metal na sua estrutura, apresentando planos com difração larga correspondentes a fases amorfas de carbono e carbono grafite. Para a amostra C/Zn3,0\%, foram observados picos correspondentes a óxido de zinco encontrado em valores próximos de $2 \theta$ igual $26,26^{\circ}$. As amostras C/Zn5,0\% e C/Zn10,0\% apresentaram picos de difração de óxido de zinco em valores de $2 \theta$ entre $31^{\circ}$ a $69^{\circ}$, indicando que o carvão ativado sofreu modificações na sua estrutura pela deposição de zinco.

\subsection{EXPERIMENTOS DE ATIVIDADE ANTIBACTERIANA}

A eficiência bacteriológica dos filtros com $\mathrm{C} / \mathrm{Zn}$ em relação à remoção de Escherichia coli da água está mostrada na TAB. 3

Tabela 3

Eficiência bacteriológica dos filtros com carvão ativado sem impregnação e com carvão ativado impregnado com zinco na condição inicial $(5 \%)$ e na condição final (95\%) da vida útil dos filtros ${ }^{(*)}$

\begin{tabular}{ccc}
\hline Filtro $^{(2)}$ & $\begin{array}{c}\text { Condição Inicial } \\
(5 \%)^{(1)}\end{array}$ & $\begin{array}{c}\text { Condição Final } \\
(95 \%)^{(1)}\end{array}$ \\
\hline C Puro & $15,84 \pm 0,59 \mathrm{Aa}$ & $23,05 \pm 0,65 \mathrm{Ab}$ \\
C/Zn 1,0\% & $66,44 \pm 0,42 \mathrm{Bb}$ & $61,63 \pm 0,51 \mathrm{Da}$ \\
C/Zn 3,0\% & $69,02 \pm 0,72 \mathrm{Cb}$ & $31,43 \pm 0,81 \mathrm{Ba}$ \\
C/Zn 5,0\% & $82,14 \pm 0,63 \mathrm{Db}$ & $55,41 \pm 0,65 \mathrm{Ca}$ \\
C/Zn 10,0\% & $99,83 \pm 0,31 \mathrm{Ea}$ & $99,56 \pm 0,36 \mathrm{Ea}$
\end{tabular}

${ }^{*}$ Resultados expressos em valores médios \pm desvio padrão. Analise de Variância (ANOVA) com p-valor $=0,001$. (1) Dentro de uma mesma coluna, as médias seguidas por mesma letra (Maiúsculas) não diferem estatisticamente entre si, pelo teste de Tukey a 5\% de nível de significância. (2) Para uma mesma linha, as médias seguidas por mesma letra (Minúsculas) não diferem estatisticamente entre si, pelo teste de Tukey a $5 \%$ de nível de significância.
Dos resultados da análise estatística mostrados na TAB.3, verificou-se que houve diferença estatisticamente significativa na remoção de Escherichia coli entre os filtros com C Puro, C/Zn1,0\%, $\mathrm{C} / \mathrm{Zn} 3,0 \%$, C/Zn5,0\% e C/Zn10,0\% e também nas remoções na condição inicial (5\%) e na condição final (95\%), com exceção do filtro com C/Zn10,0\%.

Os filtros com $\mathrm{C} / \mathrm{Zn}$ mostraram eficiência de remoção de Escherichia coli da água superior em relação ao filtro com carvão ativado sem impregnação (C Puro), verificando o efeito que o metal zinco exerce sobre as bactérias.

Na condição final (95\%) da vida útil dos filtros, com exceção do filtro $\mathrm{C} / \mathrm{Zn} 10,0 \%$, observou-se que as remoções foram menores em relação às remoções na condição inicial $(5 \%)$ da vida útil do filtro. A menor eficiência bacteriológica observada, provavelmente é devido a menor quantidade de metais presentes na estrutura do carvão ativado durante a percolação dos 570 L de água, ocasionada pela lixiviação de zinco fracamente adsorvida na superfície do material. (MPENYANA-MONYATSI et al., 2012; ZHAO et al. 2013).

O filtro com a amostra de carvão ativado impregnado com a maior concentração de zinco, C/Zn10,0\%, apresentou a melhor eficiência bacteriológica em relação aos outros filtros com carvão ativado impregnado com menores concentrações de zinco, alcançando uma remoção de $99,83 \%$ na condição inicial (5\%) e remoção de $99,56 \%$ na condição final (95\%) da vida útil do filtro. Portanto, a concentração de zinco com $10 \%$ impregnada no carvão ativado foi necessária para inativar e causar a morte das bactérias. O filtro com $\mathrm{C} / \mathrm{Zn} 10,0 \%$ atendeu aos critérios de eficiência bacteriológica estabelecida pela ABNT NBR 16098:2012, sendo superior a 99\%, proporcionando uma melhoria na qualidade bacteriológica da água. 


\subsection{DETERMINAÇÃo DE EXTRAíveIS}

Os resultados das análises para determinação da concentração de extraíveis, especificamente o metal zinco, realizados na condição inicial (5\%) e na condição final (95\%) da vida útil dos filtros, são mostrados na TAB. 4.

Tabela 4

Concentração de extraíveis lixiviados na água filtrada na condição inicial ( $5 \%$ e na condição final $(95 \%)$ da vida útil ${ }^{(*)}$

\begin{tabular}{|c|c|c|c|}
\hline Filtro ${ }^{(2)}$ & $\begin{array}{l}\text { Condição } \\
\text { Inicial (5\%) } \\
\left(\mathrm{mg} \cdot \mathrm{L}^{-1}\right)^{(1)}\end{array}$ & $\begin{array}{l}\text { Condição Final } \\
\qquad(95 \%) \\
\left(m g \cdot L^{-1}\right)^{(1)}\end{array}$ & $\begin{array}{c}\text { NBR } \\
\text { 16098:2012 } \\
\text { Portaria } \\
2914: 2011 \\
\left(\mathrm{mg} \cdot \mathrm{L}^{-1}\right)\end{array}$ \\
\hline $\mathrm{C} / \mathrm{Zn} 1,0 \%$ & $1,01 \pm 0,01 \mathrm{Ab}$ & $0,47 \pm 0,02 \mathrm{Aa}$ & \\
\hline $\mathrm{C} / \mathrm{Zn} 3,0 \%$ & $1,87 \pm 0,03 \mathrm{Bb}$ & $0,72 \pm 0,02 \mathrm{Ba}$ & 5 \\
\hline $\mathrm{C} / \mathrm{Zn} 5,0 \%$ & $2,70 \pm 0,03 \mathrm{Cb}$ & $0,90 \pm 0,02 \mathrm{Ca}$ & \\
\hline $\mathrm{C} / \mathrm{Zn} 10,0 \%$ & $3,53 \pm 0,02 \mathrm{Db}$ & $0,92 \pm 0,04 \mathrm{Ca}$ & \\
\hline
\end{tabular}

* Resultados expressos em valores médios \pm desvio padrão. Analise de Variância (ANOVA) com p-valor $=0,0058$. (1) Dentro de uma mesma coluna, as médias seguidas por mesma letra (Maiúsculas) não diferem estatisticamente entre si, pelo teste de Tukey a $5 \%$ de nível de significância. (2) Para uma mesma linha, as médias seguidas por mesma letra (Minúsculas) não diferem estatisticamente entre si, pelo teste de Tukey a 5\% de nível de significância.

De acordo com os resultados de lixiviação mostrados na TAB. 4, verificou-se que houve diferença estatisticamente significativa na concentração de extraíveis presentes na água filtrada entre os filtros analisados, exceto para a condição final (95\%) nos filtros com $\mathrm{C} / \mathrm{Zn} 5,0 \%$ e $\mathrm{C} / \mathrm{Zn} 10,0 \%$, onde os valores não diferem estatisticamente entre si. A concentração de extraíveis lixiviada na água foi maior com o aumento da concentração de zinco impregnado no carvão ativado. Contudo, todos os filtros analisados encontrou-se dentro dos limites estabelecidos pela ABNT NBR 15176/2004 e pela Portaria 2914/2011 do Ministério da Saúde, sendo a concentração de zinco inferior a $5 \mathrm{mg} \cdot \mathrm{L}^{-1}$.

\section{CONCLUSÕES}

A impregnação de zinco no carvão ativado granular promoveu modificações nas suas características originais, havendo a obstrução parcial dos poros do carvão ativado original, diminuindo assim seu volume e área superficial, e aumentando a sua microporosidade. A impregnação de zinco no carvão ativado influenciou na remoção de bactérias Escherichia coli da água, e a eficiência foi superior com o aumento da concentração do metal. A eficiência de remoção de Escherichia coli da água do filtro com C/Zn10\% foi superior a $99 \%$, atendendo ao critério de eficiência bacteriológica estabelecida pela ABNT NBR 16098:2012, proporcionando uma melhoria na qualidade microbiológica da água. Portanto, a purificação de água com filtros de carvão ativado impregnado com metais pode ser utilizada como um tratamento alternativo no controle da qualidade microbiológica da água em áreas em onde as condições de saneamento são precárias ou mesmo onde a população não possui acesso à água potável.

\section{Agradecimentos}

Á Coordenação de Aperfeiçoamento de Pessoal de Nível Superior (CAPES) pelo apoio financeiro. E ao Complexo de Centrais de Apoio à Pesquisa (COMCAP) da Universidade Estadual de Maringá (UEM) pela realização das análises de Difração de Raio-X (DRX). 


\section{REFERÊNCIAS}

ABNT - NBR 16098: Aparelho para melhoria da qualidade da água para consumo humano Requisitos e Métodos de ensaio. Rio de Janeiro, setembro, 2012. $34 \mathrm{p}$.

AKSU, Z.; TATH,A.I.; TUNÇ,O. A comparative adsorption biosorption study of acid blue 161: Effect of temperature on equilibrium and kinetic parameters, Chemical Engineering Journal, v. 142, p.23-29, 2008.

APHA - American Public Health Association, Standard Methods for the Examination of Water and Wastewater, 21st, Centennial Edition, Washington, 2005.

BANDYOPADHYAYA R.; SIVAIAH M.V.; SHANKAR, P.A. Silverembedded granular activated carbon as an antibacterial medium for water purification. Journal of Chemical Technology Biotechnololy, v. 83, p.11771180, 2008

BERTRAND R.; ROIG, B. Evaluation of enrichmentfree PCR-based detection on the $\mathrm{rbE}$ gene of Escherichia coli 0157 - Application to municipal wastewater. Water Research, v. 41, p.1280-1286, 2007.

BRASIL (2011). Portaria no 2914. Ministério da Saúde. Estabelece os procedimentos e responsabilidades relativos ao controle e vigilância da qualidade da água para consumo humano e seu padrão de potabilidade. Brasília: Ministério da Saúde. Diário Oficial da União. 14 de dezembro de 2011.

BRUNAUER, S.; EMMETT, P.H.; TELLER, E. Adsorption of gases in multimolecular layers. Journal of the American Chemical Society, v. 60, p.309-319, 1968.

CHENG, H.; DASTGHEIB, S.A.; KARANFIL, T. Adsorption of dissolved natural organic matter by modified activated carbons, Water Ressearch., v. 39, p. 2281-2290, 2005.

CHOUDHURY, R.; SRIVASTAVA, S. Zinc resistence mechanism in bactéria, Current Science, v.81, p.768775, 2001.

GARCIA-ARMISEN, T., SERVAIS, P. Respectives contributions of point and non-point sources of $E$. coli and enterococci in a large urbanized watershed (the Seine river - France). Journal of Environmental Management, v. 82, p. 512-518, 2007.

GAUDEN, P.A.; SZMECHTIG-GAUDEN, E.; RYCHLICKI, G.; DUBER, S.; GARBACZ, J.K.; BUCZKOWSKI, R. Changes of the porous estructure of activated carbons applied in a filter bed pilot operation, Journal of Colloid and Interface Science, v. 295, p.327-347, 2006.

GOPAL, K.; TRIPATHY, S.S.; BERSILLON, J.L.; DUBEY, S.P. Chlorination byproducts, their toxicodynamics and removal from drinking water, Journal Hazardous Materials, v. 140, p.1-6, 2007.

HALSEY, G. Physical adsorption on non-uniform surfaces. Journal of Chemical Physics, v. 16, p.931 937, 1948.

HAMDAOUI, O.; NAFFRECHOW, E. Modeling of adsorption isotherms of phenol and chlorofenols onto granular activated carbon. Part I. Two-parameter models and equations allowing determination of thermodynamic parameters. Journal of Hazardous Materials, v.147, p. 381-394, 2007.

HÖRMAN, A., RIMHANNEN-FINNE, R., MAUNULA, L., VON BONSDORFF, C.H.,TORVELA, N., HEIKINHEIMO, A., HA"NNINEN, M.L. Campylobacter spp., Giardia spp., Cryptosporidum spp., noroviruses, and indicator organisms in surfacewater in South western Finland, 2000 e 2001. Applied and Environmental Microbiology, v. 70, p. 87-95, 2004.

HORVATH, G.; KAWAZOE, K. Method for the calculation of effective pore size distribution in molecular sieve carbons. Journal of Chemical Engineering Japan, v. 16, p.470-475, 1983.

JAGUARIBE, E. F.; MEDEIROS, L. L.; BARRETO, M. C. S.; ARAÚJO, L. P. The performance of activated carbons from sugarcane bagasse, babassu, and coconut shells in removing residual chlorine, Brazilian Journal of Chemical Engineering, v. 22, p. 41-47, 2005.

KENNEDY, L.J.; KUMAR, A.G.; RAVINDRAN, B.; SEKARAN, G. Copper impregnated mesosporous activated carbon as a high efficient catalyst for the complete destruction of pathogens in water, Environmetal Progress, v. 27, p.40-50, 2007.

MAIOLI, C.; BESTETTI, A.; MAURI, A.; POZZATO, C.; PARONI, R. Removal of radioisotopes in solution and bactericidal/bacteriostatic sterilising power an activated carbon and metal silver filters. Environmental Toxicology and Pharmacology, v. 27,p.49-53, 2009.

MCQUAIG, S.M., SCOTT, T.M., HARWOOD, V.J., FARRAH, S.R., LUKASIK, J. Detection of humanderived fecal pollution in environmental waters by use of a PCR-based human polyomavirus assay, Applied and Environmental Microbiology, v. 72, p. 7567757, 2006. 
MPENYANA-MONYATSI, L.; MTHOMBENI, N. H.; ONYANGO, M. S.; MOMBA, MAGGY N. B. Costeffective filter materials coated with silver nanoparticles for the removal of pathogenic bacteria in groundwater. International Journal of Environmental Research and Public Health, v. 9, p. 244-271, 2012.

NANGMENYI, G.; XAO, W.; MEHRABI, S.; MINTZ, E.; ECONOMY, J. Bactericidal activity of Ag nanoparticleimpregnated fibreglass for water disinfection, Journal Water Health, v. 7, p. 657-663, 2009.

OH, W.C. Properties of metal supported porous carbon and bactericidal effects. Journal of Industrial and Engineering Chemistry, v. 9, p. 117-124, 2003.

PAREY, V. P. Relevância de Parâmetros de Qualidade das Águas Aplicados à Águas Correntes. Fundação Nacional do Meio Ambiente FATMA, Florianópolis, p. 13-62, 1999.

PETER-VARBANETS, M.; ZURBRÜGG C.; SWARTZ, C.; PRONK, W. Decentralized systems for potable water and the potential of membrane technology. Water Research, v. 43, p. 245-265, 2009.

PHAN,N.H.; RIO,S.; FAUR,C.; LE,C.L; LE C.P.; NGUYEN, T.H. Production of fibrous activated carbons from natural cellulose (jut, coconut) fibers for water treatment applications, Carbon, v. 44, p. 2821-2824, 2006.

POPE, M. L.; BUSSEN, M.; FEIGE, M. A.; SHADIX, L.; GONDER, S.; RODGERS, C.; CHAMBERS,Y.; PULZ, J.; MILLER, K.; CONNELL,K.; STANDRIDGE, J. Assessment of the Effects of Holding Time and Temperature on Escherichia coli Densities in Surface Water Samples. Applied of Environmetal Microbiology, v. 69, p. 6201-6207, 2003.

QUANTACHROME INSTRUMENTS, User Manual, Nova series windows-based operating and data analysis software, Nova win, 2002.
RAZVIGOROVA, M.; BUDINOVA, T.; PETROV, N.; MINKOVA, V. Purification of water by activated carbons from apricot stones, lignites and anthracite, Water Research, v. 32, p. 2135-2139, 1998.

SILVER, S.; WALDERHAUG, M. Encyclopaedia of Microbiology. (Ed. Lederberg, J.), Academic Press, San Diego, v. 2, 1992.

SORLINI, S.; COLLIVIGNARELLI, C. Chlorite removal with granular activated carbon. Desalination, 176, 255-265, 2005.

SU, F.; LUO, M..; ZHANG, F.; LI, P.; LOU, K.; XING, $X$. Performance of microbiological control by a point-ofuse filter system for drinking water purification, Journal of Environmetal Sciences, v.21, p.12371246, 2009.

YAMAMOTO, O.; NAKAKOSHI, K.; SASAMOTO, T.; NAKAGAWA, H.; MIURA, K. Adsorption and growth inhibition of bacteria on carbon containing zinc oxide. Carbon, 39, 1643-1651, 2001.

YUN, C. H.; PARK, Y. H.; PARK, C. R. Effect of precarbonization on porosity development of activated carbons from rice straw, Carbon. 39, p. 559-571, 2001.

ZHAO, Y.; WANG, Z-Q.; ZHAO, X.; LI, W.; LIU, S-X. Antibacterial action of silver-doped activated carbon prepared by vacuum impregnation, Applied Surface Science, v.266, 67-72, 2013.

ZIESE, T.; ANDERSON, Y.; DE JONG, B.; LÖFDAHL, S.; RAMBERG, M. Surto de Escherichia coli 0157 na Suécia. Relatórios de investigação de surtos. v.1, n.1, 1996.16p. 